\title{
LIMITES INSTITUCIONAIS AO DESENVOLVIMENTO DE PROPOSTAS PEDAGÓGICAS INTERCULTURAIS NA PÓS-GRADUAÇÃO: OBSERVAÇÕES SOBRE O MESPT/UNB
}

\author{
LAYLA JORGE TEIXEIRA CESAR
}

\begin{abstract}
RESUMO
0 presente artigo pretende tratar dos limites institucionais identificados no desenvolvimento de propostas pedagógicas interculturais na pós-graduação a partir de observações empíricas realizadas junto ao Mestrado em Sustentabilidade junto a Povos e Terras Tradicionais da Universidade de Brasília (MESPT/UnB) entre 2017 e 2018. 0 foco da análise se concentra nas práticas de ensino e aprendizagem e nas atividades de pesquisa e dissertação. Para tanto, foi realizada uma breve revisão literária, considerando as noções de validação científica e pluralidade epistêmica. Esta revisão é seguida por um resumo das observações baseadas na minha experiência com o MESPT, destacando as estratégias desenvolvidas pelo programa para superar ou contornar alguns dos limites institucionais enfrentados.
\end{abstract}

Palavras-Chave

Educação intercultural; Pós-graduação; Pluralidade epistêmica.

\section{INSTITUTIONAL LIMITS TO THE DEVELOPMENT OFINTERCULTURAL PEDAGOGICAL PROPOSALS IN GRADUATE STUDIES: OBSERVATIONS ON THE MESPT/UNB}

\begin{abstract}
This article intends to address the institutional limits identified in the development of intercultural pedagogical proposals in postgraduate studies based on empirical observations carried out in the Master in Sustainability with Traditional Peoples and Lands of the University of Brasília (MESPT/UnB) between 2017 and 2018.The analysis focuses on learning and teaching practices and on the student's research activities. We also conduct a brief literary review considering the notions of scientific validation and epistemic plurality. This review is followed by a summary of observations based on my own experience with MESPT, highlighting the strategies developed by this program to overcome or circumvent some of the institutional limits faced.
\end{abstract}

KEYWORDS

Intercultural education; Postgraduate studies; Epistemic plurality.

\section{LIMITES INSTITUCIONALES AL DESARROLLO DE PROPUESTAS PEDAGÓGICAS INTERCULTURALES EN ESTUDIOS DE POSGRADO: OBSERVACIONES SOBRE EL MESPT/UNB}

\section{RESUMEN}

Este artículo pretende abordar los límites institucionales identificados en el desarrollo de propuestas pedagógicas interculturales en estudios de posgrado a partir de observaciones empíricas realizadas con la Maestría en Sostenibilidad con los Pueblos y Tierras Tradicionales de la Universidad de Brasilia (MESPT/UnB) entre 2017 y 2018. El enfoque del análisis se basa en las prácticas de aprendizaje y enseñanza y las actividades de investigación del estudiante. Para ello, se realizó una breve revisión literaria, considerando las nociones de validación científica y pluralidad epistémica. A esta revisión le sigue un resumen de observaciones basadas en mi experiencia con MESPT, destacando las estrategias desarrolladas por el programa para superar o sortear algunos de los límites institucionales enfrentados. 
Educación intercultural; Posgraduación; Pluralidad epistémica

LIMITES INSTITUTIONNELLES AU DÉVELOPPEMENT DE PROPOSITIONS PÉDAGOGIQUES INTERCULTURELLES DANS LES ÉTUDES SUPÉRIEURES: OBSRVATIONS SUR LE MESPT/UNB

\section{RÉSUMÉ}

Cet article entend aborder les limites institutionnelles identifiées dans le développement de propositions pédagogiques interculturelles dans les études de troisième cycle sur la base des observations empiriques menées avec le Master en Durabilité avec les Peuples et les Terres Traditionnelles de l'Université de Brasília (MESPT/UnB) entre 2017 et 2018. L'analyse se concentre sur les pratiques d'apprentissage et d'enseignement et sur les activités de recherche de l'étudiant. A cet effet, une brève revue littéraire, prenant en compte les notions de validation scientifique et de pluralité épistémique, a été menée. Cette revue est suivie d'un résumé des observations basées sur mon expérience avec MESPT, mettant en évidence les stratégies développées par le programme pour surmonter ou contourner certaines des limites institutionnelles rencontrées.

\section{MOTS CLÉS}

Éducation interculturelle; Études supérieures; Pluralité épistémique. 


\section{INTRODUÇÃO}

O presente artigo pretende tratar dos limites institucionais identificados no desenvolvimento de propostas pedagógicas interculturais na pós-graduação. Para tanto, parto de alguns dos resultados de minha pesquisa de doutoramento, fruto do diálogo com as/os discentes, docentes e servidoras/es que constituem o Mestrado em Sustentabilidade junto a Povos e Terras Tradicionais (MESPT) da Universidade de Brasília (UnB).

Inicialmente, cabe destacar que o MESPT é o único programa intercultural de pósgraduação de toda a região Centro-Oeste. É direcionado a receber estudantes indígenas, quilombolas e membros de povos e comunidades tradicionais, como retireiros, geraizeiros ou povos rom, entre outros.

O fato de estar localizado em Brasília tem dois efeitos importantes: o primeiro diz respeito à mobilidade, por estar no centro do país. Disso resulta que a composição das turmas reúna estudantes de todas as regiões do Brasil.

O segundo efeito é a relevância política da capital, que faz de Brasília uma rota para a militância por direitos para indígenas, quilombolas e de povos e comunidades tradicionais. Além da negociação direta com os órgãos públicos, a cidade reúne também eventos de caráter nacional como a Conferência Nacional de Política Indigenista ou o Acampamento Terra Livre. O programa é, portanto, um polo para a criação de redes de articulação e apoio às/aos estudantes em suas demandas políticas.

De fato, se pode observar entre as/os egressas/os do MESPT os desdobramentos desta articulação política, bem como a aplicação prática das pesquisas produzidas. Algumas das dissertações publicadas no programa, por exemplo, foram utilizadas como subsídio a processos de demarcação dos territórios originários das/os estudantes. Outras, se tornaram material para o desenvolvimento de ações educativas, na elaboração de cartilhas para educação intercultural de jovens e crianças. Além disso, o prestígio conferido pelo diploma de pós-graduação também abriu portas para a participação das/os egressas/os em diversos eventos nacionais e internacionais na condição de palestrantes.

Nesse sentido, o programa alcança resultados muito positivos. Seus benefícios, todavia, poderiam ser potencializados se a interculturalidade fosse aplicada como princípio organizador de toda a instituição, em todos os seus cursos e práticas administrativas. A razão para ampliar a interculturalidade sobre toda a universidade é evidente: o anti-racismo só se constrói com a educação das pessoas que produzem o racismo, e que se beneficiam dele.

Sobre este tema, ainda é preciso frisar o óbvio: a diversidade cultural não é vivida apenas por pessoas negras e afrocentradas, quilombolas, indígenas ou membros de outros povos e comunidades tradicionais. Pessoas brancas também convivem com a diversidade, e vêm sendo ensinadas a silenciá-la, a partir de perspectivas racistas. Assim, a educação 
intercultural é uma oportunidade para que aprendam sobre a diferença, e desaprendam sobre o monopólio da razão.

O principal objetivo da minha pesquisa foi identificar os limites institucionais impostos ao MESPT que impedem o desenvolvimento pleno de sua proposta intercultural, ilustrando como o racismo institucional da universidade pode impor obstáculos a ações interculturais. Este artigo se concentrará nas atividades realizadas em sala de aula e na condução das pesquisas de dissertação das/os estudantes. Para tanto, realizarei uma breve revisão literária sobre o tema, considerando as noções de validação científica e pluralidade epistêmica, debatendo a questão do acesso ao real.

A metodologia que direcionou minha pesquisa foi a análise situacional, baseada na etnografia institucional que realizei entre os anos de 2017 e 2018 acompanhando as aulas e eventos do programa, bem como entrevistas com discentes e docentes e análise documental de currículos, projetos político-pedagógicos do MESPT e fichas de avaliação da CAPES.

\section{REVISÃO DE LITERATURA: A CULTURA E O MONOPÓLIO DA VERDADE}

Discutir a questão da interculturalidade é, fundamentalmente, discutir o racismo. Em especial, o racismo epistêmico, isto é, a hierarquização das manifestações culturais incluídas aí todas as formas de produção de conhecimento - segundo a raça atribuída a quem as produziu. Esta hierarquização foi organizada pela branquitude, através de violentas ações de coação física e moral, como pedra fundamental do processo colonizatório. A branquitude instalou, então, a si própria no topo da escala epistêmica como única detentora do acesso ao real e à produção de conhecimento verdadeiro (QUIJANO, 2007; GROSFOGUEL, 2016).

A ciência ocidental se funda sobre essa retórica de exclusividade (SOUSA SANTOS, 2002). Supõe a si mesma como universal e procura esconder os rastros de sua própria origem e desenvolvimento, marcados pela apropriação de conhecimentos de diversos outros povos - frequentemente sem o devido crédito.

O chamado "conhecimento tradicional", por exemplo, não possuiria uma existência autônoma sob esta perspectiva, sendo interpretado como expressão cultural localizada de um grupo, ligado às suas tradições, sem alcance ou validade universal.

A expressão máxima do racismo epistêmico é o epistemicídio. Segundo Sueli Carneiro (2005), o epistemicídio não é apenas um processo de negação e exclusão, mas a produção ativa de mecanismos de deslegitimação. A carência material, a privação de recursos e a discriminação tornam-se, nesta perspectiva, tecnologias de dominação.

Para combater o racismo epistêmico, é necessário promover o reconhecimento da legitimidade de discursos não-brancos na definição do real (CARNEIRO, 2005; SOUSA 
SANTOS, 1995; 2002). A superação da lógica ocidental de monocultura do saber passa pelo reconhecimento de que também a ciência ocidental possui limites. Esta ponderação é proposta através da educação intercultural e do diálogo com saberes não-acadêmicos.

\section{O DIÁLOGO COM A CIÊNCIA}

Para entendermos melhor como a ciência cartesiana se organiza, podemos acompanhar a análise de Hugh Lacey e Pablo Mariconda (2014) sobre a interação entre a atividade científica - formada por valores cognitivos - e a prática social que a contamina formada por valores sociais, éticos, políticos, religiosos, etc.

Para os autores, a atividade científica poderia ser dividida em 5 etapas: 1) a adoção da estratégia de pesquisa, incluindo o recorte a ser estudado e a proposição de hipóteses; 2) a escolha do método e o empreendimento da pesquisa; 3) a avaliação cognitiva das teorias e hipóteses; 4) a disseminação de resultados científicos; 5) a aplicação do conhecimento científico produzido.

A prática da ciência de fato, que envolveria exclusivamente valores cognitivos, existiria apenas na etapa 3. Somente aí se poderia falar em contato objetivo com o real, guiado pela empiria. Tudo o que se processa antes, nas etapas 1 e 2, referentes à organização das agendas de pesquisa e à escolha dos métodos, e tudo o que vem depois deste ponto, nas etapas 4 e 5, referentes à maneira como estes resultados serão divulgados, transformados em tecnologias e aplicados, seria fruto de valores sociais.

Segundo os autores, estes valores têm um papel legítimo e, por vezes, essencial na estruturação da pesquisa. Nas primeiras e últimas etapas, as questões de identidade e cultura se tornariam preponderantes. Assim, ainda que a atividade científica tenha sido executada com consistência e coerência internas, e seus resultados sejam objetivos e válidos, a limitação das etapas que a antecedem, implica em que estes resultados não possam ser considerados absolutos e nem esgotem o real. Outros insumos nas etapas 1 e 2, por exemplo, poderiam direcionar a produção científica em uma trajetória completamente distinta, nos revelando outra face do real que, caso contrário, permaneceria oculta - como a Lua, que só tem um dos lados iluminado pelo Sol.

Por outro lado, se nos arriscarmos a ampliar esta leitura cartesiana, e compreendermos que as próprias ideias de "evidência" e "experiência empírica" também são limitadas, então mesmo a etapa 3 deve ser discutida. Para as/os realistas, como Lacey e Mariconda (2014), a experiência se reduz ao que é informado ao raciocínio pelos sentidos do corpo - visão, audição, tato, paladar, olfato. Os autores não consideram como reais outras formas de informação da experiência. 
Tudo o que é transcendental, religioso ou imaterial, por exemplo, seria anticientífico segundo este posicionamento. Nesse sentido, a educação intercultural, que pode abarcar elementos transcendentais, não é apenas um diálogo entre modos de vida, senão um diálogo entre concepções sobre a própria natureza do real. A disputa se dá na ordem da ontologia (o que é ou não real, independentemente dos sujeitos) e na ordem da epistemologia (quais sentidos conferem acesso a este real).

Esta ampliação da percepção dos sentidos sobre um real imaterial está presente em várias das pesquisas desenvolvidas no âmbito do MESPT. A espiritualidade, por exemplo, é considerada, com frequência, uma dimensão que constitui o real a tal ponto que dela se possa extrair dados de pesquisa.

É importante atentar para que a defesa da educação intercultural não tenha como efeito secundário - e indesejado - tornar-se argumento para a defesa do que hoje se denomina como "pós-verdade". Por isso devemos buscar definir critérios que permitam reconhecer os saberes tradicionais como formas genuínas de produção do conhecimento, e que os diferenciem de meras opiniões ou criações individuais.

Talvez a diferença mais relevante seja o fato de que as pós-verdades carregam o signo da racionalidade moderna: são excludentes e se pretendem absolutas. Procuram se tornar narrativas hegemônicas. Não são formas de saber capazes de coexistir com as demais - exatamente o oposto do que se busca com o diálogo entre saberes.

Além disso, os saberes tradicionais não constituem informações isoladas. São corpos inteiros de saber, cuja trajetória social e histórica é possível retraçar. Possuem métodos e técnicas próprios e podem ser transmitidos ou ensinados. São saberes integrados à racionalidade dos povos e comunidades que os produzem, e organizam a sua realidade social.

Os sujeitos que compartilham estes saberes atestam a sua efetividade sobre o real. A título de exemplo, se pode citar o catálogo apurinã de plantas medicinais registrado pelo mestre Alan Miguel Apurinã em sua dissertação no MESPT (APURINÃ, 2018). Trata-se de um guia de aplicação prática do manejo de plantas curativas que envolveu elementos transcendentais em sua elaboração, como a consulta a entidades espirituais, cujos saberes, segundo o próprio autor, só puderam ser acessados porque ele mesmo tinha a devida iniciação espiritual.

Dificilmente a efetividade destes saberes poderia ser medida por critérios modernos porque, em geral, se trata de saberes que não seguem a lógica da reprodutibilidade ou da previsibilidade. Ainda no exemplo do catálogo medicinal apurinã, algumas plantas serão curativas para determinados sujeitos, mas não para outros, e não poderia haver testagem massiva de sua eficiência. A limitação dos critérios modernos, todavia, não pode ser justificativa para o silenciamento destes saberes. 
Abigail Aguillera e Leonardo Helland (2011) em sua pesquisa sobre as práticas de educação intercultural no México também observam que, se desejamos construir interações interculturais de longo prazo, é necessário pensar novos modos de validação que não privilegiem apenas alguns tipos de conhecimento em detrimento de outros.

Segundo as/os autoras/es, já há no México demonstrações de práticas que combinam conhecimentos indígenas e metodologias cientificamente validadas em diferentes campos do saber. Ainda assim, não foi possível superar o sentido da hierarquização moderna. Os conhecimentos indígenas, afirmam, continuariam sendo vistos como saberes complementares ao conhecimento científico, e considerados apenas na medida em que sejam compatíveis com a lógica ocidental. Não são tidos como modos de reorganização da ciência e da sociedade.

Рara as/os autoras/es, isto se explica parcialmente pelo fato de que os conhecimentos indígenas resistem à autoridade positivista da racionalidade empiricista ocidental. Não são grafocêntricos, individualizados e padronizados para reprodução como os saberes científicos. Se explica também pelo fato de que os conhecimentos indígenas desafiem os sistemas legais de propriedade intelectual, considerando autoria, patente ou posse em geral. Assim, se posicionam de modo contrário à lógica do capitalismo acadêmico mas potencialmente a favor da equidade epistêmica.

É importante frisar que não se está reivindicando o status de ciência moderna para os saberes tradicionais - que historicamente resistem à modernidade. Não se trata de uma disputa. Tampouco se deve reduzi-los a experiências estéticas. Nem ciência, nem arte, os saberes tradicionais possuiriam um estatuto especial dentro da academia no contexto da educação intercultural. Participando da universidade, suas lógicas poderiam contribuir para a organização da realidade social fora dos espaços dos povos e comunidades onde se originam.

Não pretendo aqui debater longamente o estabelecimento de critérios de validação para saberes tradicionais ou oferecer conclusões a esta questão de caráter filosófico sobre a natureza do conhecimento - ou do próprio real. Pretendo tão somente me concentrar na análise do processo de marginalização dos saberes tradicionais como ferramenta de legitimação da desigualdade de acesso a recursos materiais e da violência contra os sujeitos que os produzem.

Cabe observar, assim, que a ciência produzida nas universidades ocidentalizadas se consolidou, ao longo da história, sobre uma série de opções políticas e culturais que não só limitaram os seus produtos mas também, por vezes, produziram resultados violentos.

Como afirma Ramon Grosfoguel (2016), no período entre os séculos XV e XVI as bases do conhecimento moderno ocidental se consolidaram através da apropriação de conhecimentos produzidos por outras fontes, ao mesmo tempo em que estas fontes eram silenciadas por meio de genocídios e epistemicídios. Foi o caso da violência praticada contra 
muçulmanos e judeus na conquista de Al-Andalus; povos originários das Américas a partir da colonização; povos africanos na tomada da África e na escravização dos mesmos para tráfico humano em escala global; e contra as mulheres europeias queimadas vivas acusadas de bruxaria (GROSFOGUEL, 2016; FEDERICI, 2017).

O processo de exclusão destes sujeitos na construção de agendas de pesquisa e na definição do método científico, segundo Grosfoguel, teria sido uma estratégia do homem branco europeu para a manutenção do seu privilégio, desenhando os contornos que deveria assumir o capitalismo global.

A exclusão é contrária ao exercício de uma ciência livre. Toda cultura desenvolve soluções para o manejo do mundo. É preciso criar pontes ou traduções entre culturas, de modo que as agendas de pesquisa e a definição dos métodos, tanto em termos éticos como práticos, possam ser construídas coletivamente.

Naturalmente, também há casos em que a compatibilidade entre experiências não é possível. Onde as diferenças entre culturas são, como diria Manuela Carneiro da Cunha (2007), incomensuráveis, e as perspectivas sobre o real são tão distintas que nenhuma tradução poderia criar congruências. Então, é relevante nos lembrarmos que os saberes e as ciências são discursos criados para cumprir funções sociais distintas.

A impossibilidade de tradução não é um obstáculo à coexistência, porque não há disputa. No caso da incomensurabilidade, a diversidade cultural na educação superior se refere à possibilidade de que a universidade seja também um espaço para o ensino de saberes de ordem não-científica. O objetivo de uma educação diversa não é necessariamente uma síntese, mas sim a convivência entre distintas lógicas desenvolvidas na relação com o real, que representem múltiplos projetos morais e de distribuição de recursos materiais.

\section{A EXPERIÊNCIA DO MESPT}

O MESPT não existe de maneira autônoma, mas sim vinculado à Universidade de Brasília. O seu funcionamento, portanto, é restrito pela própria instituição, física e administrativamente. Alguns dos limites institucionais se referem mais diretamente a questões estruturais, como o espaço físico, o tempo, e as normas que regulam a universidade. Outros, se referem aos conteúdos dessa estrutura, como o desenvolvimento das pesquisas e as práticas pedagógicas. Ambas as dimensões são expressões ideológicas da racionalidade ocidental e, sempre que resistem ao diálogo com saberes e práticas de povos e comunidades tradicionais, revelam a prática do racismo epistêmico.

O MESPT é um primoroso exemplo de esforço para combater o racismo epistêmico e construir formas de diálogo. Aqui, me concentrarei sobre as práticas em sala de aula e o desenvolvimento das pesquisas de dissertação no âmbito do programa, apontando, quando 
for o caso, as inovações propostas pelo MESPT para superar ou contornar eventuais obstáculos institucionais:

- O desenvolvimento das pesquisas: O programa estimula o uso de metodologias não-convencionais, na medida em que estas dialoguem com as visões de mundo das/os estudantes. É fácil perceber como os jargões próprios da academia estão presentes nas descrições que as/os estudantes fazem de suas pesquisas, como "análise de dados" ou "coleta de dados", ou ainda o uso de métodos e técnicas também próprios do fazer acadêmico, como questionários e entrevistas semiestruturadas. Há, contudo, uma série de inovações ou particularidades na maneira como as informações são acessadas, e os formatos de organização dos dados são customizados para a perspectiva de cada povo e comunidade.

Em trabalho publicado em 2018, por exemplo, o mestre John Santiago, quilombola do território de Jambuaçu, descreve sua metodologia em três "tempos": o "tempo memória", para identificação e análise de documentos históricos da comunidade; o "tempo rebeldia", рага análise das narrativas das lideranças políticas da comunidade; e o "tempo esperança", рага a análise da atualidade das estratégias de resistência da comunidade (SANTIAGO, 2018, p.32).

Já Valdelice Verón, em trabalho publicado também em 2018, descreve sua metodologia como uma apropriação do método etnográfico desenvolvido pela antropologia. A diferença em relação a este, descreve a autora, é que ao invés do ponto de vista único da pesquisadora, sua "etnografia kaiowá" é constituída de modo coletivo por múltiplos olhares, todos femininos. Verón destaca ainda que o êxito na investigação dependeu da sua educação espiritual, caso contrário não poderia compreender o que the é informado em campo (VERÓN, 2018, p.11).

Creuza Krahô também afirma que seu trabalho se aproxima do que seria "uma abordagem antropológica" para a "ciência dos cupen", as/os brancas/os, mas que esta é apenas uma tradução aproximada para explicar seu processo de vivência, ou de "conhecerpesquisar", orientado pelas/os mais velhas/os de sua comunidade ao longo da pesquisa (KRAHÔ, 2017, p. 17).

O livre formato de pesquisa e escrita permite que as/os estudantes utilizem uma grande variedade de fontes de informações e referências. Isto inclui a interlocução tanto com autoras/es reconhecidas/os e consolidadas/os dentro da academia como com as/os autoras/es e referências de suas próprias comunidades, seja através de registros escritos ou orais. Para ampliar esta interlocução, o programa prevê também que os trabalhos possam ser apresentados nos idiomas de cada estudante, quando o português não seja sua primeira língua. A limitação, neste caso, é que ainda seja obrigatório apresentar também uma tradução para o português, que continua sendo o idioma de referência. 
Na definição das agendas de pesquisa, métodos e abordagens selecionados, há ainda abertura para a expressão de uma dimensão transcendental/espiritual/imaterial. Sobre esse tema, afirma uma docente, em palestra aberta ao público no $3^{\circ}$ Congresso Internacional de Povos Indígenas da América Latina (CIPIAL):

As pesquisas do MESPT são ancestralmente orientadas. Isso é mais que só uma força de expressão. De fato tem implicações importantes para as temporalidades e para as formas como as pesquisas são conduzidas. Dou um exemplo: em duas pesquisas, uma em terreiro e uma em quilombo, as pesquisas foram mudando de feição, os temas e os percursos metodológicos foram sendo alterados no processo, porque a ancestralidade comunicava isso para as/os estudantes através das suas reuniões comunitárias (Notas de evento CIPIAL - docente).

Com relação ao conteúdo, há um direcionamento político bastante explícito e preocupado com os impactos dos produtos. A mesma docente define que:

Uma das primeiras coisas que a gente discute com essas/es alunas/os é que as pesquisas são necessariamente pesquisas engajadas. Pesquisas que precisam ser construídas com a comunidade, sempre compreendida como um sujeito epistêmico, ou seja, não são pesquisas desenvolvidas solitariamente, como em geral os programas convencionais costumam orientar as/os estudantes nesses processos formativos. (...) Então as pesquisas das/os nossas/os estudantes são sempre produzidas a partir da comunidade, em diálogo com a comunidade, a tal ponto que o que a gente considera é que elas/es fazem uma pesquisa com autoria comunitária. (...) Nossa preocupação também é que o programa não se transforme num espaço de elaboração teórica e deixe de ter consequências importantes para os contextos a partir dos quais elas são desenvolvidas. Acho que elas [as pesquisas] têm de fato algum tipo de incidência sobre as realidades a partir das quais elas são desenvolvidas (Notas de evento - CIPIAL - docente).

Os processos de pesquisa são, em geral, realizados de modo coletivo, por toda a comunidade da/o pesquisadora/pesquisador. O direcionamento do programa é que os temas pesquisados visem atender aos interesses dos povos. Os efeitos práticos deste engajamento comunitário são confirmados por uma série de desdobramentos já alcançados pelas dissertações e trabalhos defendidos até o momento, que subsidiaram processos de reconhecimento étnico e demarcação territorial nas comunidades das/os estudantes que os produziram.

O que também diferencia o processo de pesquisa no MESPT é que as/os estudantes serão sempre pesquisadoras/es com acesso privilegiado aos seus campos de pesquisa. Oferecerão sempre visões a partir de dentro das comunidades. Uma perspectiva que nenhuma/nenhum outra/o pesquisadora/pesquisador poderia oferecer. Isso permite o protagonismo dos povos e comunidades tradicionais na construção de narrativas sobre suas próprias realidades, e combate a estereotipificação produzida por trabalhos que acessam estas realidades apenas de modo superficial.

A despeito da condução coletiva das pesquisas, facilmente constatada no conteúdo dos seus produtos, uma restrição institucional significativa ao programa é o fato de que a universidade - submetida a critérios externos de credenciamento e avaliação - permite apenas a autoria individual dos trabalhos, bem como a emissão de diplomas no nome de uma 
única pessoa. Isso impede que a lógica de coletividade na produção dos saberes possa ser institucionalmente reconhecida. Uma característica do capitalismo acadêmico, que define o diploma como uma moeda de capital social (SLAUGHTER; LESLIE, 1997).

Finalmente, as defesas dos trabalhos, na conclusão do processo de pesquisa, se assemelham em estrutura a qualquer outra defesa de mestrado na universidade, com banca composta por dois docentes e convidadas/os externas/os. O que as diferencia é que, entre estas/es convidadas/os, devem figurar representantes das comunidades das/os discentes, o que abre um importante canal de diálogo e oferece uma validação política, além da validação acadêmica dos trabalhos apresentados.

Além disso, as defesas podem ser realizadas fora do espaço da universidade, nos territórios das/os estudantes, o que evidencia a intenção do programa em buscar o engajamento das comunidades no diálogo com a academia. Outro diferencial importante é a realização de dinâmicas envolvendo cantos e danças, recorrente nas sessões de defesa, e que deslocam o sentido de esterilidade emocional e espiritual habituais da academia.

- As práticas pedagógicas: As aulas do MESPT são, em geral, organizadas como em qualquer outra pós-graduação na área de humanas, girando em torno do debate dos textos, com ocasionais dinâmicas de grupo. Os trabalhos de avaliação das disciplinas possuem formatos variados, desde a redação de artigos até dinâmicas em grupo envolvendo histórias orais.

Por força do espaço e do tempo reservados, as aulas são apenas teóricas, sem dimensão prática. Algumas disciplinas se apresentam bem adequadas aos padrões da academia, com aulas que expressam a separação cartesiana entre corpo e mente, concentrando a aprendizagem só na dimensão intelectual.

Já outras procuram recuperar a dimensão do corpo na aprendizagem, com momentos de canto e dança, trazidos pelas/os estudantes. Estas dinâmicas em grupo iniciam e/ou encerram os encontros e abrem espaço para o que foi definido, em variados momentos do programa, como uma "dimensão espiritual" da aprendizagem. Como afirma uma professora:

A academia foca muito nos processos mentais. Nos contextos de produção do conhecimento, aprendizagem, ou transmissão do conhecimento onde esses sujeitos [atravessados pela transcendentalidade] estão em maioria, as chaves do processo do conhecimento se modificam. Não é mais o mental, é o espiritual. São outras dimensões da vida (Notas de evento - CIPIAL - docente).

Observa-se, assim, que as disciplinas do programa não são conduzidas de modo idêntico pelas/os diferentes docentes. Estas contradições são marcas das trajetórias de formação disciplinar vividas pelas/os próprias/os docentes que, grosso modo, receberam elas/es mesmas/os uma educação convencional. Resultam também do fato de que a interculturalidade na educação superior, especialmente na pós-graduação, constitui uma 
experiência recente, e o MESPT ainda seja um programa jovem. A ideia de interculturalidade está em processo de elaboração e práticas pedagógicas são diariamente construídas.

As contradições nos posicionamentos entre docentes aparecem também quando se observa as distintas compreensões expressas sobre a finalidade do programa. Рага algumas/ns, a prioridade do MESPT deve ser oferecer às/aos estudantes o ferramental convencional da academia, para que dominem os métodos e regras da produção do conhecimento ocidental e possam se emancipar em relação a este. Para outras/os, o inverso: o MESPT deve ser tratado como um espaço de valorização dos saberes tradicionais, e está escusado de cumprir qualquer rito acadêmico.

A maioria das/os docentes parece posicionar-se buscando o equilíbrio entre estes dois polos. Nem supervalorizam os conhecimentos tradicionais, o que poderia resultar na sua fetichização ou folclorização, ou os antagonizar em relação ao conhecimento acadêmico; nem supervalorizam o domínio dos conhecimentos acadêmicos, o que poderia resultar no apagamento do diálogo entre culturas.

O que há de notavelmente inovador nas práticas pedagógicas propostas não é, portanto, uma técnica determinada. O que diferencia o MESPT é a disposição das/dos docentes em ouvir e aprender. É uma opção política por oferecer um espaço de diálogo, que não exige insumos especiais. Um nível de diálogo que poderia ser realizado em qualquer outro curso em que existisse esta vontade.

Não significa que o diálogo seja sempre perfeito. Pelo contrário, trata-se precisamente de reconhecer que haverão incomensurabilidades entre os saberes. Nem sempre haverá traduções comuns que possam ser compreendidas por todos - e por vezes alguns saberes estrategicamente deixarão de ser compartilhados pelas/os estudantes.

Além disso, para um exercício efetivo da interculturalidade, a disposição das/os docentes precisa ser acompanhada por uma reforma estrutural. Novas dinâmicas de relação com o espaço e o tempo - encontros fora da universidade, sem horários cronometrados, por exemplo - podem contribuir para aprimorar as condições de diálogo.

\section{A HIBRIDIZAÇÃO COMO RESULTADO DO DIÁLOGO}

No contexto da educação intercultural, provavelmente são as/os estudantes com origens contra-hegemônicas as/os que melhores condições têm de apresentar produtos interculturais de fato, porque podem transitar entre as suas lógicas de mundo originárias e a lógica ocidental apreendida na academia. Ainda assim, pode-se dizer que todos os membros da comunidade acadêmica envolvidos neste processo são influenciados pelo contato entre diferentes racionalidades. 
O resultado é uma hibridização da experiência dos sujeitos. Tanto as/os estudantes membros de povos e comunidades tradicionais absorvem o vocabulário, as práticas, e as perspectivas da academia, como as/os estudantes e docentes ocidentais se tornam sensiveis às racionalidades tradicionais. Note-se que essa influência mútua está longe de ser simétrica, já que as trocas e diálogos ocorrem no espaço físico e institucional da academia, o que favorece a racionalidade ocidental.

Hooks (2013) também chama atenção em seu trabalho para as dificuldades em se falar de um diálogo verdadeiramente simétrico entre saberes quando são os sujeitos marginalizados que devem se deslocar de suas comunidades para entrar no espaço das instituições brancas. Ou seja, renunciam a estarem no centro de seus mundos para se colocarem à margem do mundo branco e realizar a dessegregação.

Entre os elementos que mais se destacam na formação de produtos dialógicos híbridos estão a afetividade e a transcendentalidade. A afetividade implica a vinculação política entre os sujeitos e seus trabalhos de investigação. Passa pelo reconhecimento de que todo projeto acadêmico implica também um projeto ético. Se relaciona também à conexão física e emocional entre os sujeitos, que se realiza através do toque, dos cantos e danças, dos momentos de troca nas turmas, dentro e fora de sala de aula. Um exercício de humanização do espaço da academia.

O MESPT reúne agendas de pesquisa intimamente relacionadas às biografias de suas/seus estudantes, e o seu compartilhamento é sempre carregado de emoção. Os momentos de troca sobre as pesquisas com frequência incluem informações politicamente relevantes para a sobrevivência das comunidades. Isto faz com que o conjunto de docentes e discentes forme mais que uma comunidade acadêmica. É o que, por repetidas vezes, discentes e docentes nomearam como uma "comunidade de confiança".

A transcendentalidade, por sua vez, se expressa na relação com o imaterial ou o espiritual, presente nas falas e pesquisas de estudantes indígenas, quilombolas e membros de comunidades tradicionais. Participa tanto da definição de agendas de investigação como da elaboração de métodos. Dados coletados a partir de referências imateriais também constituem evidências empíricas, nestes termos. Sob este ponto de vista, é a racionalidade científica moderna que estaria incompleta e poderia ser complementada por outras perspectivas.

De forma ilustrativa a esta questão, observemos em maior detalhe a metodologia utilizada por Alan Apurinã (2018) em sua dissertação de mestrado defendida no MESPT, já suprarreferida:

\footnotetext{
"Trata-se de um jeito de pesquisa apurinã da aldeia Kamapa. Nesse tipo de pesquisa, cabe ao pesquisador total respeito, seguindo o padrão das pessoas do local a ser estudado, do jeito deles, seja acompanhando as pessoas numa pescaria, numa caçada, num encontro de uma planta medicinal, numa abertura de um roçado, na construção
} 
de uma maloca, em um processo de cura, em uma cerimônia das passagens de espíritos ou numa contação de histórias. Durante esse processo, surgiram as respostas que esperava adquirir, respeitando os limites de cada sujeito" (p. 27).

O autor descreve em sua dissertação a relação entre o pajé Arywka e a "Maloca das medicinas"1 como duas entidades cuja dinâmica de interação se dá em dimensões imateriais e é estruturante da sociedade apurinã em sua aldeia. Isto é, as plantas e o seu espaço de cultivo teriam identidades próprias. Somado a isto, a cerimônia a que se refere não estaria sendo apenas observada, num sentido etnográfico, senão também vivenciada pelo pesquisador, que compartilha do seu sentido. Isto é, o pesquisador não é um espectador participante das cerimônias de passagem de espíritos, mas as vivencia de fato. Por sua condição de iniciado, o autor também pode estabelecer comunicação com estas entidades.

No momento de avaliação do trabalho no âmbito do programa, coube reconhecer a impossibilidade de que a investigação fosse submetida a critérios científicos ordinários de validação. A aprovação do estudante indicou a abertura ao diálogo com formas de produção do saber baseadas em evidências transcendentais.

Outro exemplo significativo deste processo de hibridização é a forma como as/os docentes demonstram o seu envolvimento com os processos transcendentais que atravessam o programa. Como afirmou uma docente durante o CIPIAL:

Nos últimos dois anos fomos submetidos a processos de descredenciamento e a processos de submissão de nova proposta pela CAPES, e a gente tem muita clareza que as espiritualidades dos territórios influenciaram as decisões que a gente tomava aqui. As decisões tomadas eram decisões difíceis, e acabaram sendo acertadas. E nós sabemos que as/os estudantes pediam aos encantados e faziam suas rezas (Notas de evento - CIPIAL docente B).

Este foi apenas um dos momentos em que alguma/algum docente manifestou reconhecer a dimensão transcendental como real. Foram recorrentes os relatos de docentes que ampliaram sua sensibilidade neste sentido ao longo de sua participação no programa, evidenciando como também estariam sendo influenciadas/os pelo contato com racionalidades não-ocidentais.

\section{CONSIDERAÇÕES FINAIS}

Pude perceber duas perspectivas principais em relação à função do diálogo intercultural, apresentadas pela literatura e confirmadas pela experiência com o MESPT. Ambas convivem nos discursos dos sujeitos que participam do programa.

A primeira, mais superficial, vê a interculturalidade como uma concessão por parte da academia. Nesse caso, a produção científica da universidade seguiria incontestada,

\footnotetext{
${ }^{1}$ Espaço onde se cultivam as plantas medicinais.
} 
enquanto a instituição consentiria a presença de sujeitos contra-hegemônicos, num exercício mais próximo da tolerância que da real convivência.

O foco recairia então sobre o direito de acesso à universidade como um exercício de cidadania. Nesse sentido, a função da educação intercultural seria munir as/os estudantes do ferramental acadêmico hegemônico, a fim de ampliar sua autonomia e sua capacidade de trânsito nas instituições do Estado. Esta compreensão é limitada porque, ao criar espaços de educação intercultural apenas para atender a anseios éticos ou políticos, o resultado é um multiculturalismo de inclusão (TUBINO, 2013), e não um diálogo, de fato, entre saberes.

A segunda perspectiva, mais profunda, percebe a interculturalidade como uma questão epistêmica. É a própria natureza do conhecimento que é colocada em xeque. Se reconhece a realidade daquilo que o Ocidente nomeia como imaterial, espiritual ou transcendental, por exemplo. Ou ainda se reconhece que saberes que não atendam a critérios de objetividade científica, segundo padrões cartesianos, possam ser considerados narrativas verdadeiras sobre o real e coexistir com saberes ocidentais dentro da academia.

Nesse sentido, a função da educação intercultural passaria pela restruturação das formas de produção do conhecimento, de modo a considerar como legítimas formas nãoocidentais de produção do saber a partir de métodos e parâmetros de verdade diversos. Através deste reconhecimento, lógicas contra-hegemônicas poderiam encontrar maior espaço para subsidiar a formação das narrativas que organizam a sociedade e, assim, promover justiça material e epistêmica.

\section{REFERÊNCIAS}

AGUILLERA, Abigail; HELLAND, Leonardo. Beyond Acculturation: Political "Change", Indigenous Knowledges, and Intercultural Higher-Education in Mexico. Journal for Critical Education Policy Studies, v. 9, n. 2, p. 286-296, 2011.

APURINÃ, Alan Miguel. Maloca das medicinas e sua relação com 0 pajé Arywka. Dissertação de Mestrado. MESPT/Unb, 2018.

CARNEIRO, Aparecida Sueli. A construção do outro como não ser como fundamento do ser. Tese de doutorado em Educação - Universidade de São Paulo, 2005.

CUNHA, Manuela Carneiro da. Relações e Dissensões entre Saberes Tradicionais e Saber Científico. Conferência realizada na Reunião da SBPC em Belém, Pará, em 12 de julho de 2007.

FEDERICl, Silvia. Calibã e a bruxa: mulheres, corpo e acumulação primitiva. São Paulo: Elefante, 2017.

GROSFOGUEL, Ramon. A Estrutura do Conhecimento nas Universidades Ocidentalizadas: racismo/sexismo epistêmico e os quatro genocídios/epistemicídios do longo século XVI. Revista Sociedade e Estado, v. 31, n. 1, p. 25-49, 2016. 
H0OKS, bell. Ensinado a transgredir: a educação como prática da liberdade. São Paulo: Martins Fontes, 2013.

KRAHÔ, Creuza. Wato ne hômpu ne kãmpa: Convivo, vejo e ouço a vida Mehi (Mãkrarè). Dissertação de Mestrado, Universidade de Brasília, Brasília, 2017.

LACEY, H.; MARICONDA, P. 0 modelo da interação entre as atividades científicas e os valores na interpretação das práticas científicas contemporâneas. Estudos Avançados, v. 28, n. 82, p. 181-199, 2014.

QUIJANO, A. Colonialidad del poder y clasificacion social. In: GOMEZ, Santiago Castro; GROSFOGUEL, Ramon. El girodecolonial. Reflexiones para una diversidad epistémica más allá del capitalismo global. Bogota: Siglo del Hombre Editores, 2007. p. 285-327.

SANTIAGO, John. Comunidades Quilombolas de Jambuaçu, Moju-Pa, contra as Agroestratégias do Capital: Juventude e Territorios de R-Existências. Dissertação de mestrado, Universidade de Brasília, Brasília, 2018.

SLAUGHTER, S.; LESLIE, L. Academic capitalism: Politics, policies and the entrepreneurial university. Maryland: John Hopkins University press, 1997.

SOUSA SANTOS, Boaventura. Pela Mão de Alice. São Paulo: Cortez Editora, 1995.

SOUSA SANTOS, Boaventura, Para uma Sociologia das ausências e uma Sociologia das emergências. Revista Crítica de Ciências Sociais, v. 63, 2002.

TUBINO, Fidel. La interculturalidad crítica como proyecto ético-político. Encuentro continental de educadores agustinos, Lima, janeiro, p. 24-28, 2005. Disponível em: <http://oala.villanova.edu/congresos/educación/ lima-ponen-02.html>.

VERÓN, Valdelice. Tekombo'e kunhakoty: modo de viver da mulher kaiowa. Dissertação de mestrado, Universidade de Brasília, Brasília, 2018.

Recebido em 15 de agosto de 2020.

Aprovado em 01 de março de 2021. 